T H E

C H E M I C A L

RE C O R D

\section{New Concepts for Regio- and Stereoselective Bis- and Triscyclopropanations of $\mathrm{C}_{60}$}

\author{
ANDREAS HIRSCH \\ Institut für Organische Chemie der Friedrich-Alexander-Universität Erlangen-Nürnberg, \\ Henkestrasse 42, 91054 Erlangen, Germany
}

Received 5 April 2005; Revised 23 May 2005; Accepted 19 May 2005

\begin{abstract}
The synthesis of isomerically multiple adducts of $\mathrm{C}_{60}$ with a defined three-dimensional structure is still one of the most challenging tasks of exohedral fullerene chemistry. The inherent regioselectivity of successive additions of addends such as malonates to the fullerene's [6,6]-double bonds is only moderate. In most cases difficult-to-isolate mixtures of regioisomers are obtained. The regioselectivity can be significantly improved if multifunctional addends able to undergo two or more additions are allowed to react with $\mathrm{C}_{60}$. Preorganization and minimization of strain energy within the addend skeleton reduce the number of sterically allowed addition patterns. Improved concepts for highly regio- and stereoselective bis- and triscyclopropanations of $\mathrm{C}_{60}$ are described. Two examples of the bisadditions with complete regioselectivity leading to trans-2- and cis-2 are presented. Here, the two malonate binding sites are linked by rigid tetraphenylporphyrin and calix-[4]-arene spacers. Selective trisadditions were achieved with the easy-to-synthesize and easy-to-modify tripodal addends 5-7, where the malonates are held together by a focal aryl moiety. Another very elegant approach for bis- and trisadditions involves cyclo- $[n]$-alkylmalonates. Selection between addition patterns with and without rotational axes is possible by choosing the right combinations of the flexible alkyl chains connecting the malonates. If alkyl chains of identical lengths are used bis- and trisadducts such as 19-21 and $\mathbf{2 5}$ with rotational symmetry are formed with high regioselectivity. These addition patterns are avoided if cyclo- $[n]$-malonates containing alkyl chains of different lengths are employed. In this case adducts such as $\mathbf{2 6}$ and $\mathbf{2 7}$ with $C_{\mathrm{s}}$-symmetry are formed. The use of the chiral cyclo-[3]-malonate $\mathbf{2 8}$ allows for the regio- and stereoselective synthesis of the enantiomerically pure $e, e, e$-trisadducts $\mathbf{2 9}$ and $\mathbf{3 0}$ containing an inherently chiral addition pattern with $C_{3}$-symmetry. (C) 2005 The Japan Chemical Journal Forum and Wiley Periodicals, Inc. Chem Rec 5: 196-208; 2005: Published online in Wiley InterScience (www.interscience.wiley.com) DOI 10.1002/tcr.20047
\end{abstract}

Key words: fullerene; cyclopropanation; malonate; regioselectivity; stereoselectivity; tether

\title{
Introduction
}

Fullerenes are multifunctional molecules with outstanding electronic, topologic, and photophysical properties. ${ }^{1}$ Usually, the most reactive sites in a fullerene are the bonds common to two hexagons $([6,6]$-bonds). They are shorter than the [5,6]-bonds fusing a hexagon and a pentagon, exhibit more
- Correspondence to: Andreas Hirsch; e-mail: andreas.hirsch@chemie.unierlangen.de 


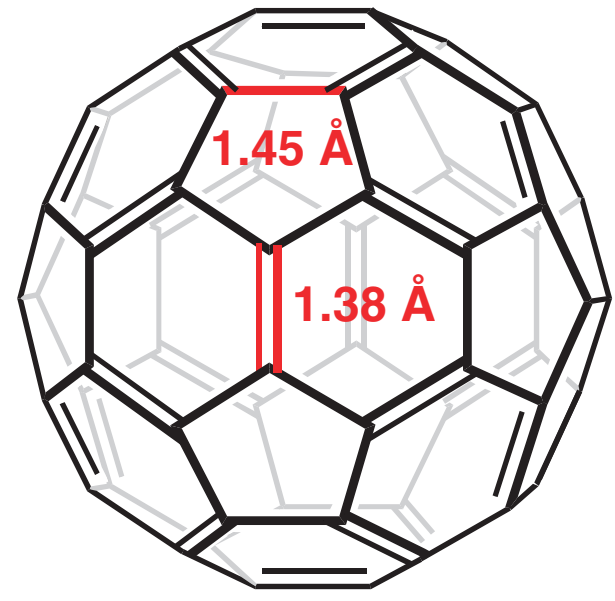

Fig. 1. VB-structure of $\mathrm{C}_{60}$ with lengths of the $[6,6]$-double bonds and $[5,6]$ single bonds.

pronounced double-bond character and, as a consequence, are susceptible to a broad variety of addition reactions such as cycloadditions. ${ }^{1}$ The major driving force for such addition reactions is the release of strain energy stored in the bent ' $\mathrm{sp}^{2}$ framework of the fullerene core. The most prominent fullerene is $\mathrm{C}_{60}$ because it is the most abundant in the raw material obtained from the usual production methods and it has the highest symmetry $\left(I_{\mathrm{h}}\right)$ (Fig. 1). $\mathrm{C}_{60}$ contains 30 identical $[6,6]$ double bonds, which guarantees that in the case of addition to one double bond (monoaddition) adducts are formed which are isomerically pure. The easiness of synthesis and characterization of monoadducts was the reason that the first period of exohedral fullerene chemistry was mainly devoted to the devel- opment of various types of monoaddition reactions. However, the polyfunctionality of $\mathrm{C}_{60}$ asks for the systematic investigation of multiple additions to the [6,6]-double bonds. The most challenging aspect in this regard is to gain control over the regio- and stereoselectivity of subsequent additions. The defined spatial arrangement of functional addends in an oligoadduct of $\mathrm{C}_{60}$ is the key for the design of compounds with interesting materials, biological, and supramolecular properties. Moreover, the degree and pattern of a multiple addition allows for fine tuning of the electronic and topologic fullerene properties.

Whereas nowadays $\mathrm{C}_{60}$ can be made in ton quantities and is comparatively inexpensive ${ }^{2}$ the application of tailor-made oligoadducts could still be hampered by high production prices if no efficient methods for their regioselective synthesis are available. A frequently applied method for the functionalization of $\mathrm{C}_{60}$ is nucleophilic cyclopropanation with malonates. ${ }^{1,3}$ Mild reaction conditions, good yields, straightforward purification, and compatibility with many functional moieties that are part of the malonate addend make this reaction very attractive. Next to the easy availability of monoadducts, hexakisadducts with an aesthetically pleasing and highly symmetrical $T_{\mathrm{h}}$-addition pattern can be easily obtained in a one-pot reaction starting from $\mathrm{C}_{60}$ using a methodology that we developed several years ago. ${ }^{4}$ Here, advantage is taken of the fact that (i) a $T_{\mathrm{h}}$-symmetrical hexakisaddition pattern is thermodynamically significantly favoured and that (ii) $\mathrm{C}_{60}$ is allowed to react in situ with an excess of a reversibly binding addend (9,10dimethylanthracene) preferably occupying octahedral sites and being replaceable by irreversible binding malonate addends. In this way we have synthesized dozens of hexakisadducts of $\mathrm{C}_{60}$

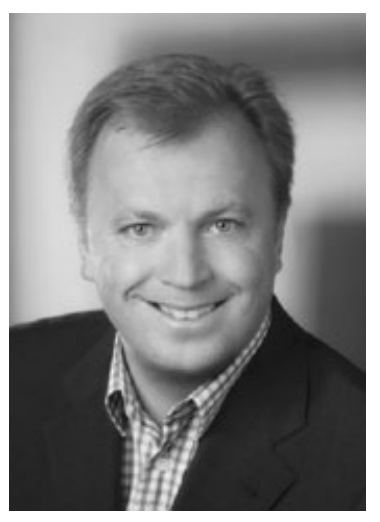

- Andreas Hirsch was born in Esslingen, Germany in 1960. He studied chemistry at the University of Tübingen, Germany where he obtained his Ph.D. in 1990 under Michael Hanack. He has carried out postdoctoral research at the Institute for Polymers and Organic Solids in Santa Barbara, California, with Fred Wudl. In 1991 he returned to Tübingen as a research associate at the Institute for Organic Chemistry. After his Habilitation in 1994 he joined the faculty of the Department of Chemistry at the University of Karlsruhe as a professor. Since October 1995, he has been Full Professor of Organic Chemistry at Friedrich-AlexanderUniversität, Erlangen-Nürnberg. Andreas Hirsch's main research activities have been focused on the development of methodologies for efficient syntheses of exohedral derivatives of fullerenes and the use of such compounds as structural templates and building blocks for supramolecular architectures and nanomaterials. Other research interests are in the area of dendrimers, calixarene conjugates, new alkynes, new types of synthetic lipids and amphiphiles, model compounds for photoinduced charge separation, chemical derivatization and solubilization of carbon nanotubes, including the investigation of their synthetic potential and properties as new materials. 


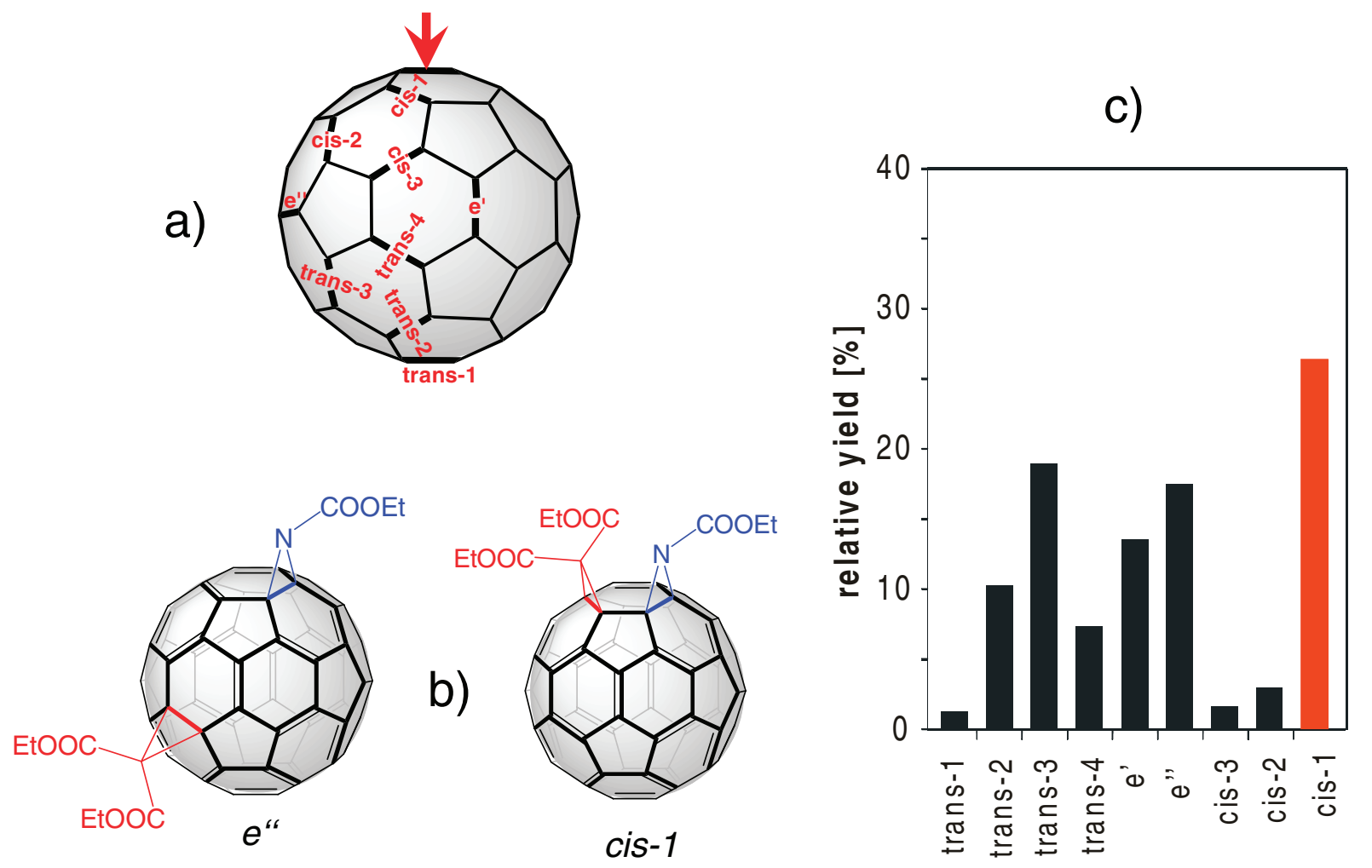

Fig. 2. a) Positional relationships of $[6,6]$-bonds with respect to the first addend in a monoadduct of $\mathrm{C}_{60}$ (the position of the first addend is marked with an arrow; b) preferred bisadducts formed by the subsequent addition of a diethyl malonate- and a nitrene addend; c) relative yields of isolated regioisomeric bisadducts of $\mathrm{C}_{61}(\mathrm{COOEt})_{2}(\mathrm{NCOOEt})$.

containing one or various types of functional addends in octahedral binding sites. Many of these spherical adducts exhibit remarkable properties. We have reviewed this subject recently. ${ }^{5}$ However, a much more difficult situation is experienced if the regioselective synthesis of lower oligoadducts such as bis- and tris-adducts is investigated.

In fact, the second addition of diethyl malonate to a monoadduct of $\mathrm{C}_{60}$ leads to a mixture of seven out of eight possible regioisomers involving the addition patterns trans-(14), e, cis-3 and cis-2 (Fig. 2). ${ }^{6}$ In the case of subsequent additions of malonate and nitrene addends, nine regioisomers are formed (Fig. 2). ${ }^{7}$ In the latter case attack of the two topologically different equatorial position $\left(e^{\prime}\right.$ and $\left.e^{\prime \prime}\right)$ give rise to different adducts and, furthermore, the cis-1-addition, which is sterically forbidden in the case of twofold malonate additions, is possible and even preferred. The common feature of this and other studies of bisadditions of segregated addends to $\mathrm{C}_{60}$ is that the inherent regioselectivity governed mainly by kinetic control is not high enough to target the efficient synthesis and isolation of a specific bisadduct. ${ }^{8}$ Although the second attack of a malonate reaction favours $e$ - and trans-3- and if possible cis- 1 addition patterns, the product mixture has to be purified by a tedious chromatographic separation. ${ }^{6,7}$ The regioselectivity of further additions to bisadducts is higher, however, the separation of isomerically pure reaction products remains difficult. ${ }^{9,10}$

\section{Concepts for Regioselective Bisadditions Using Tethered Open Chain Malonates}

The search for alternatives to this stepwise procedure, with its attendant problems outlined above, has been a challenge ever since the development of fullerene chemistry began. One way to achieve a high degree of control of the regiochemistry of additions to fullerenes is the use of tethered addend systems, for example, malonates which are connected by a more or less rigid spacer. This concept of regioselective bisfunctionalization of $\mathrm{C}_{60}$ was introduced by Diederich and coworkers. ${ }^{1,11,12,13} \mathrm{It}$ proved to be a major breakthrough and provides relatively easy access to otherwise strongly disfavoured addition patterns, such as trans-1. Similar results were obtained subsequently 

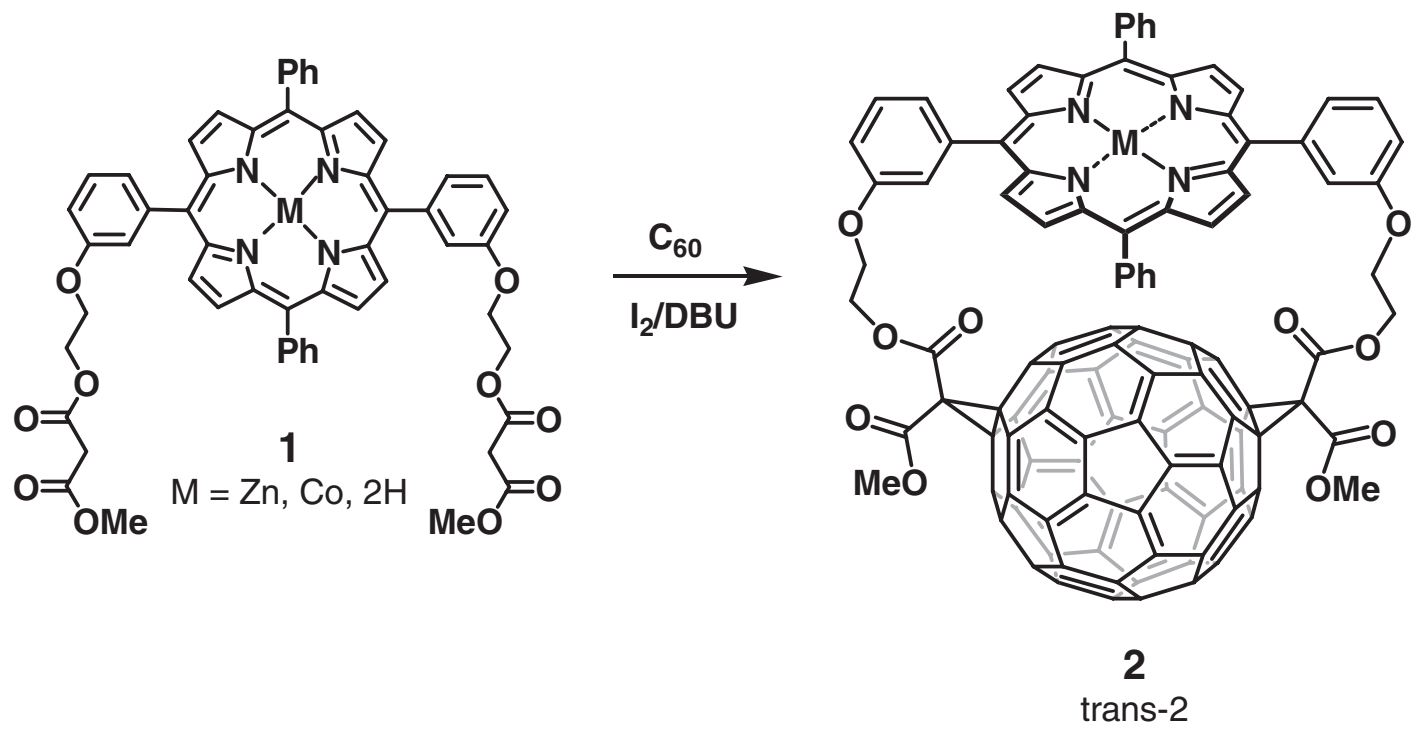

Scheme 1. Regioselective formation of doubly bridged $\mathrm{C}_{60}$-tetraphenylporphyrin dyads involving a trans-2-addition pattern.

using other types of tether-controlled addition reactions. ${ }^{14,15,16,17}$ The complex regiochemistry of $\mathrm{C}_{70}$ can also be controlled. ${ }^{18,19}$ The selectivity of the known tether methods can be very high and may lead to quite unusual addition patterns. ${ }^{20}$ Also, the diastereoelective formation of bisadducts with an inherently chiral addition pattern has been achieved by using bismalonates involving a chiral tether-like Tröger's base. ${ }^{21}$

To illustrate this concept of tether controlled bisfunctionalization, two examples investigated in our laboratories will now be presented. In an effort to design fullerene-based donor-acceptor dyads that are suitable to undergo photoinduced electron transfer we synthesized the bismalonate $\mathbf{1}$ containing a tetraphenylporphyrin moiety as rigid tether either as free base or as $\mathrm{Zn}$ and Co complex. The twofold cyclopropanation of $\mathrm{C}_{60}$ with 1 leads with complete regioselectivity to the bisadduct 2 (Scheme 1), which involves a chiral trans-2 addition pattern. ${ }^{22,23,24,25,26,27}$ The structure was unambiguously assigned using a combination of spectroscopy and computational investigations and more recently by single crystal X-ray analysis. ${ }^{28}$ The two chromophors of the very rigid architecture are held together in close proximity. The interplanar distance between the fullerene and the porphyrin is as small as $2.71 \AA$. This is considerably shorter than the interplanar distance in graphite $(3.35 \AA)$. Upon irradiation the system undergoes a photoinduced electron transfer in which one electron is transferred from the porphyrin to the fullerene moiety serving as the electron acceptor. Significantly, the back electron transfer takes place in the Marcus-inverted region, which is reflected, for example, by the longer lifetime of the charge-separated state in apolar solvents compared to more polar solvents (e.g.
619 ps in toluene vs. 38 ps in benzonitrile). This behavior is due to the very rigid structure of the dyad, in particular of the fullerene unit, causing very low reorganization energies. Fullerene-based dyads and oligoads such as $\mathbf{2}$ are currently a subject of intensive investigation with respect to the development of model systems for the photosynthetic reaction center and of solar cells. ${ }^{1}$ A similar dyad involving a trans- 1 addition pattern using a structurally modified tetraphenylporphyrin was synthesized by Diederich and coworkers. ${ }^{29}$ If tetraphenylporphyrin isomers of $\mathbf{1}$ are allowed to react with $\mathrm{C}_{60}$, where the same malonate groups are attached to adjacent instead of opposing phenyl rings, the regioselectivity changes and dyads involving an $e$ addition pattern are formed as the only regioisomers. ${ }^{26}$

Biscyclopropanation of $\mathrm{C}_{60}$ with the calix[4] arene malonate 3 afforded conjugate $\mathbf{4}$ also in complete regioselectivity exhibiting a cis-2 addition pattern (Scheme 2). ${ }^{30}$ The spacefilling model of this nano object resembles that of the FIFA world cup whose dimensions of course are many orders of magnitude larger (Fig. 3). This molecule was synthesized in our laboratory a few days before the final game of the soccer championship in 1998. We dedicated this contribution to the winning team, France. ${ }^{30}$

\section{Regioselective Formation of Trisadducts Using Tripodal Tethers}

Next to bismalonates involving rigid tethers, tripodal malonates have been used targeting the regioselective access to 


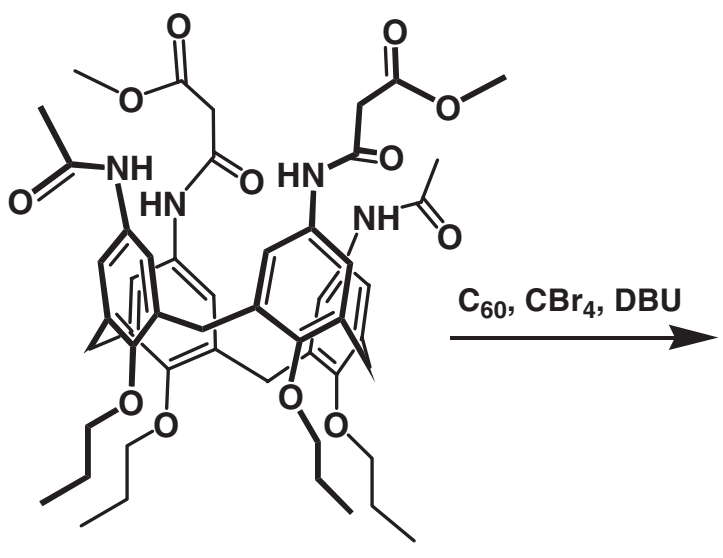

3

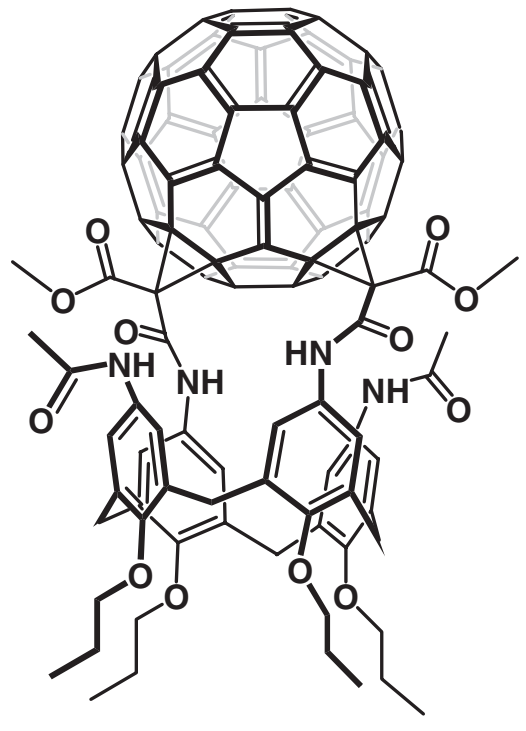

4

Scheme 2. Synthesis of the fullerene-calix[4] arene conjugate 4 involving a cis-2-addition pattern.
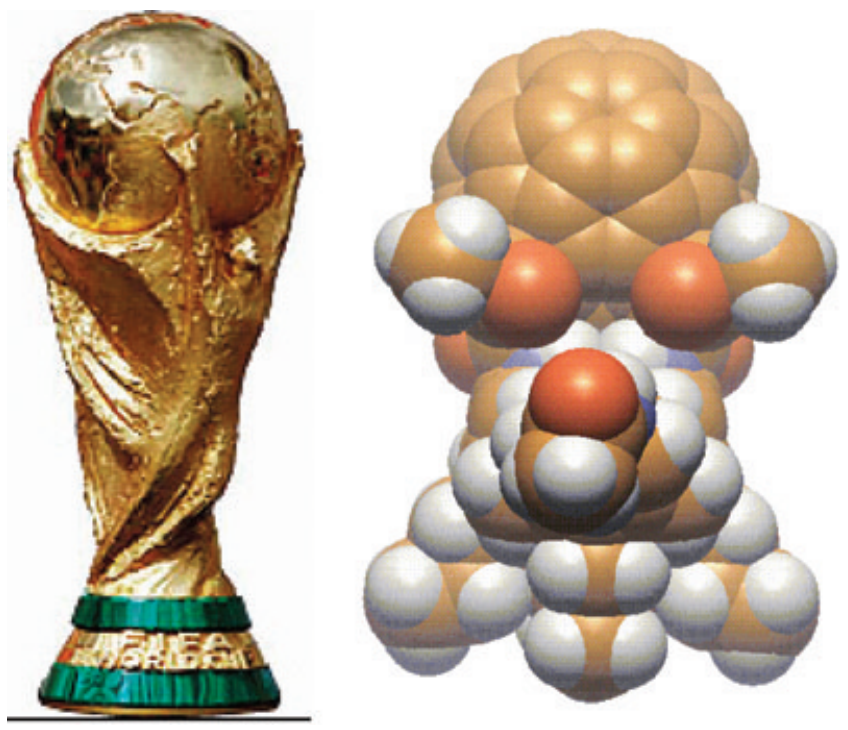

Fig. 3. Shape relationship of the football world cup (left) and the fullerenecalix[4]arene conjugate $\mathbf{4}$ as a PM3-caluclated space-filling model (right)

trisadducts of $\mathrm{C}_{60}$. As the first example a cyclotriveratrylenebased trismalonate was employed. ${ }^{31}$ The corresponding triscyclopropanation of $\mathrm{C}_{60}$ afforded roughly a 1:1 mixture of trans-3,trans-3,trans-3 and e,e,e-trisadducts. The overall yield was about $20 \%$. Although the synthesis of the tether system is not too difficult, it does require a multistep sequence.

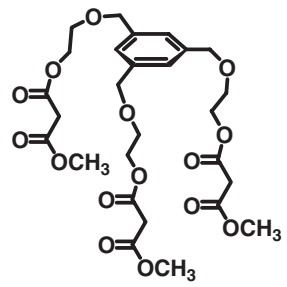

5

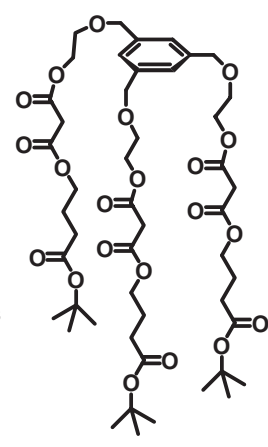

6

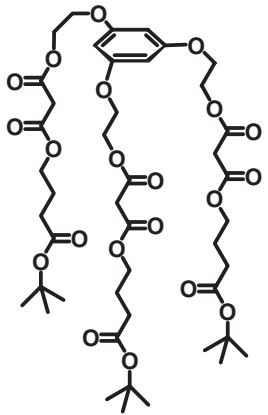

7
More recently we prepared the very simple tripodal malonates $5-7 .^{32}$

Cyclopropanation of $\mathrm{C}_{60}$ with 5-7 leads to the regioselectively preferred formation of the e,e,e-trisadducts 8-10 (Scheme 3). The best result was obtained with the malonate 7. In this case the $e, e, e$ adduct $\mathbf{1 0}$ was formed with a very pronounced regioselectivity $(100 \%)$ and can easily be isolated in $35 \%$ yield. A topologically interesting aspect associated with the trisadducts $\mathbf{8 - 1 0}$ is the preorientation of the two different sides of each malonate addend. Whereas the arms connected to the focal aryl unit are oriented towards the pole region, the freely pending side chains are oriented equatorially. Conceptually, subsequent orthogonal deprotection of the two 


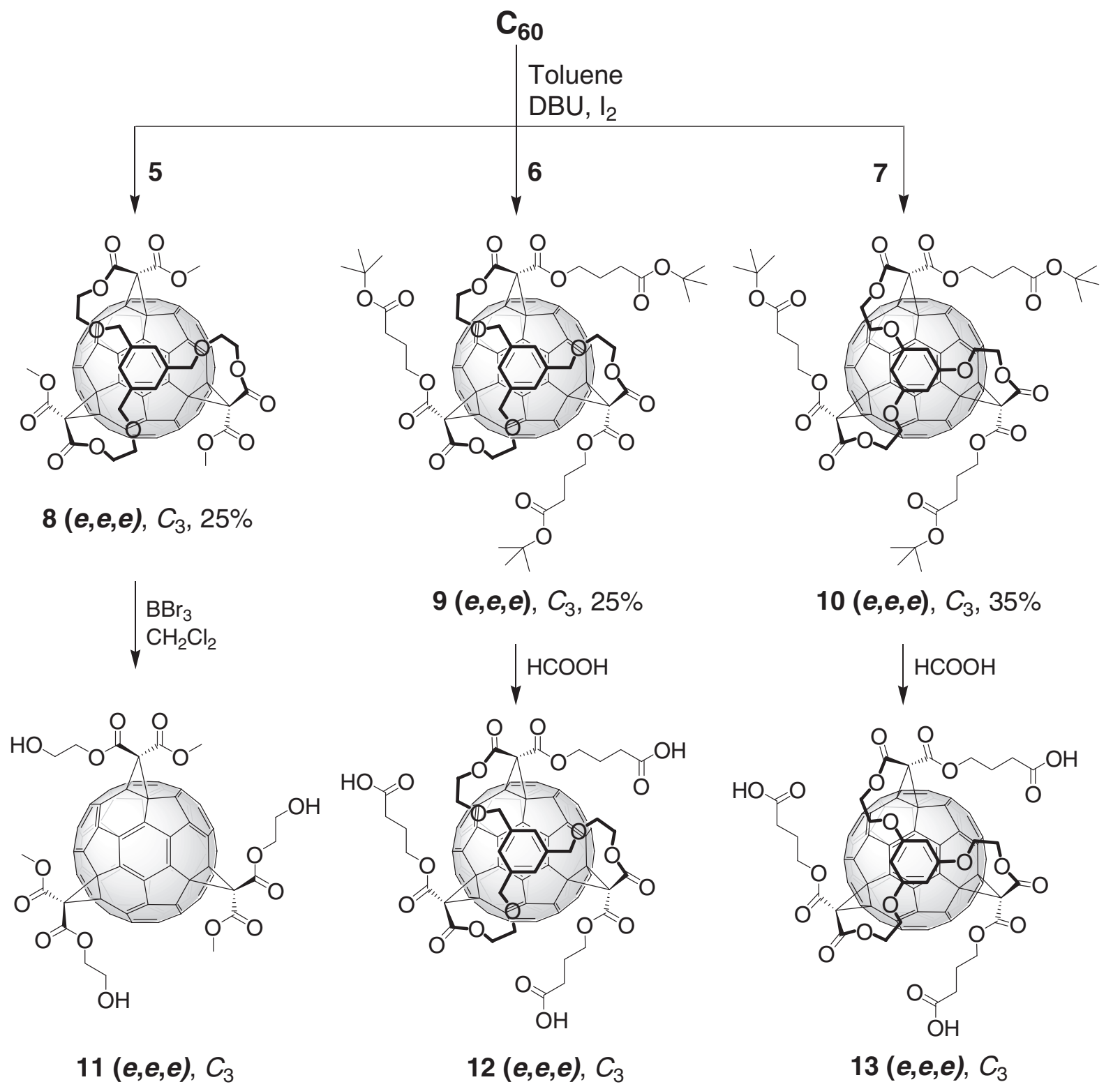

Scheme 3. Tether-directed remote functionalization of $\mathrm{C}_{60}$ with the tripodal trismalonates 5-7 and subsequent selective deprotection of the polar $(\mathbf{1 1})$ and equatorial $(\mathbf{1 2}, \mathbf{1 3})$ addend zones.

different side chains allows addressing of topologically welldefined and distinct addend zones, which could be used for further functionalization. The selective deprotection of the terminal hydroxyl groups located in the polar addend zone was achieved by the treatment of $\mathbf{8}$ with $\mathrm{BBr}_{3}$ to afford the triol 11 (Scheme 3). On the other hand the treatment of $\mathbf{9}$ and $\mathbf{1 0}$ with formic acid lead to the deprotection of the $t$-butyl ester groups within the equatorial zone to give the the trisacids 12 and 13 (Scheme 3).

\section{Highly Regioselective Functionalization Using Cyclo $[n]$ malonates}

Although the results obtained from the addition of open-chain malonates involving rigid tethers are very encouraging there are still some drawbacks, especially where the formation of bisadducts is concerned. For example, the synthesis of bismalonates containing the required rigid tether is not always straightforward and in many cases the regioselectivity is not 
complete so that elaborate separation protocols are still necessary. Furthermore, one-step synthesis to tetra- and higher adducts using open-chain tethers is still unknown. A highly satisfactory concept for a tether-controlled multiple functionalization of $\mathrm{C}_{60}$ should fulfil the following requirements: (a) easy synthesis of the malonate addends from cheap starting materials; (b) easy adaptation to a wide diversity of steric requirements; (c) possibility to attach external functionalities; (d) high yield and regioselectivity for the direct addition to $\mathrm{C}_{60}$.

These requirements are met to a large extent by an extension of the tether remote functionalization concept that we developed recently. ${ }^{33}$ The idea was to completely abandon the concept of rigid spacers and substitute for them with the most flexible and simplest system at hand, which is an alkyl chain. Of course, almost all regioselectivity would be lost, if these systems were open chained. To compensate for this we incorporated the malonates into a macrocyclic ring. This way, the regioselectivity is not based on steric preorganization, but on the avoidance of unequal strain in the alkyl chains. The corresponding macrocycles that we developed for this approach are cyclo-[n]-alkylmalonates. The number in brackets represents the number of repetition units. Examples are the cyclo-[2]octylmalonate $\mathbf{1 4}$ and the cyclo-[3]-octylmalonate $\mathbf{1 5}$ which are easily accessible by the condensation of the corresponding diol with malonyl dichloride and subsequent separation by flash chromatography.

Also larger macrocycles with four to seven repetition units are formed, however, in much lower yield. The synthesis of macrocycles with other chain lengths is also straightforward and, what it very important for the concept, also macrocycles containing alkyl chains of different lengths such as cyclo[2]-butyloctylmalonate (16) and cyclo-[2]-octyl-tetradecylmalonate (17) can easily be prepared by a statistic reaction of a 1:1 mixture of the corresponding diols and malonyl dichloride.

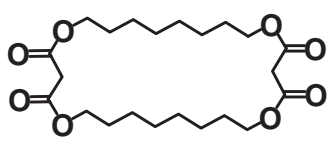

14

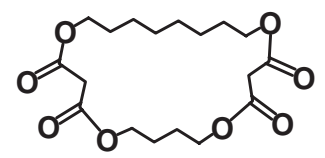

16
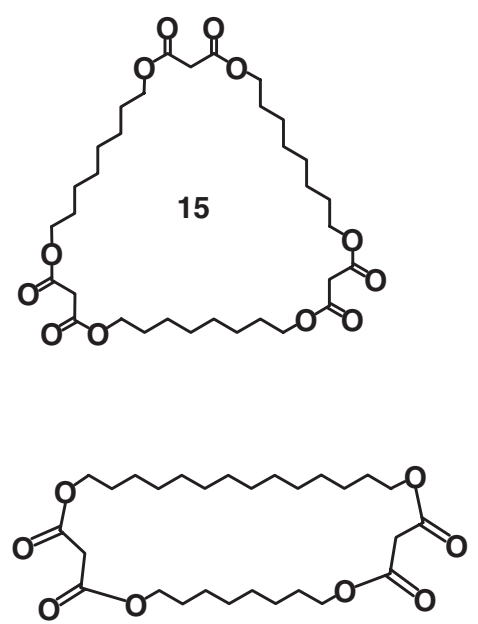

17
In principle one can distinguish different groups of bisand trisadducts, those containing rotational axes (Fig. 4) and those without rotational axes (Fig. 5). In the case of bisadducts the latter ones have a mirror plane. In bis- and trisadducts having a rotational axis, topologically indentical connections between two adjacent binding sites can be found. This is not the case for adducts lacking this symmetry element, which has important consequences for the selection of cyclo- $[n]$ malonates to be attached to $\mathrm{C}_{60}$. Due to the desired even distribution of strain energy within the alkyl bridges cyclo- $[n]$-malonates containing only one type of alkyl bridge will selectively form adducts involving rotational axes (Fig. 4). On the other hand cyclo-[n]-malonates with alkyl bridges of different length will preferably lead to the formation of adducts without rotational axes. In the case of bisadducts such molecules have a $C_{\mathrm{s}}$-symmetry (Fig. 5).

We will now present the successful proof of concept. ${ }^{33}$ Reaction of $\mathrm{C}_{60}$ with cyclo-[2]-dodecylmalonate (18) leads in complete regioselectivity and $56 \%$ isolated yield to the trans-3 adduct 19 (Scheme 4). Indeed, this adduct contains a twofold rotational axis and exhibits $C_{2}$-symmetry. Similarly, the triscyclopropanation of $\mathrm{C}_{60}$ with cyclo-[3]octylmalonate 15 leads in excellent regioselectivity (94\%) to the $C_{3}$-symmetrical trisadduct $\mathbf{2 0}$. As a minor byproduct, the olive green adduct $\mathbf{2 1}$ involving a trans-4,trans-4,trans-4addition pattern was formed (Scheme 5). This was the first example of a trisadduct having this $C_{3 \mathrm{v}}$ symmetrical addition pattern. Both $\mathbf{2 0}$ and $\mathbf{2 1}$ contain $C_{3}$ axes and as a consequence three topographically indentical connections between the adjacent binding sites are possible allowing for an even distribution of strain energy in the alkyl bridges.

Trisadduct $\mathbf{2 0}$ is a precursor of the trismalonic acid $\mathbf{2 2}$ which has generated a lot of interest because of its remarkable activity as neuroprotective antioxidant. ${ }^{34}$ This water-soluble fullerene derivative can easily be generated by hydrolysis of $\mathbf{2 0}$. Also the very selective formation of the chiral $C_{3}$-symmetrical hexakisadducts is possible using $\mathbf{2 0}$ as starting material. This is demonstrated for example with the synthesis of the amphiphile $\mathbf{2 3}$ which shows interesting $\mathrm{pH}$-switchable aggregation properties in water. ${ }^{35}$ Switching from one to another addition pattern involving rotational axes is possible when the length of the alkyl brigdes is changed. For example, allowing cyclo-[3]-tetradecylmalonate (24) instead of $\mathbf{1 5}$ to react with $\mathrm{C}_{60}$ leads to formation of the $D_{3}$-symmetrical adduct 25 where the binding sites on the $\mathrm{C}_{60}$ sphere are further remote. ${ }^{33}$

Now we move to the reactions of cyclo-[2]-malonates with two different alkyl bridges. As expected the biscyclopropanation of $\mathrm{C}_{60}$ with $\mathbf{1 6}$ and $\mathbf{1 7}$ leads in complete regioselectivity to the $C_{s}$-symmetrical adducts $\mathbf{2 6}$ and $\mathbf{2 7}$ involving a cis-2 and $e$-addition pattern (Scheme 6). In this case no topologically identical connections between the two binding sites can be found and as a consequence cyclo-[2]-malonates with two dif- 


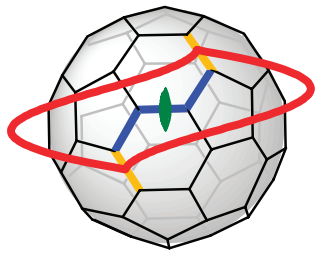

cis-3

$C_{2}$

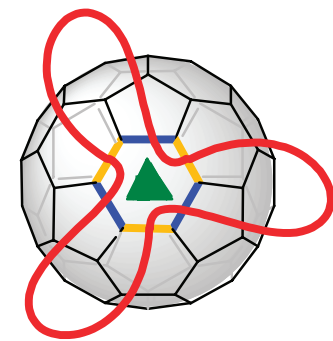

all-cis-1

$C_{3}$

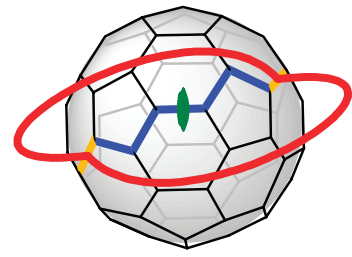

trans-3

$C_{2}$

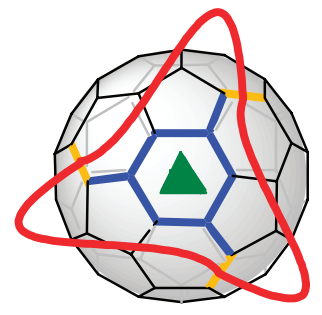

all-e

$c_{3}$

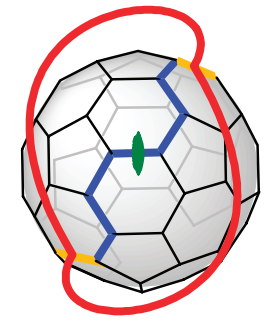

trans-2

$\mathrm{C}_{2}$

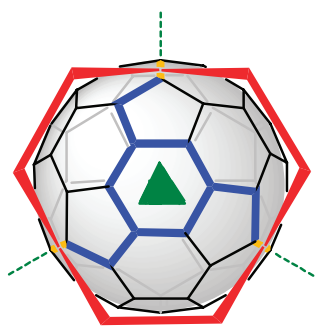

all-trans-4

$c_{3 \mathrm{v}}$

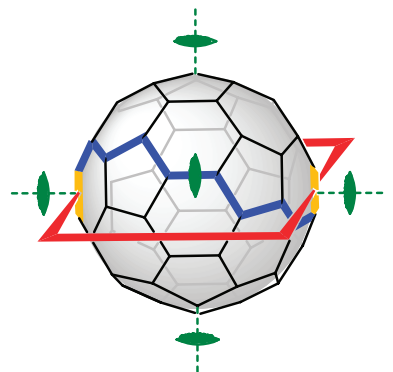

trans-1

$D_{2 h}$

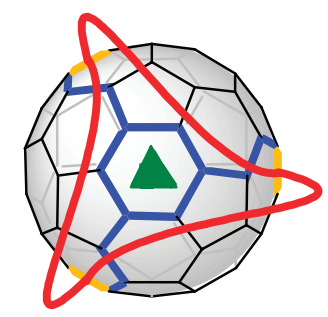

all-trans-3

$C_{3}$

Fig. 4. Possible bis- and trisadducts of $\mathrm{C}_{60}$ containing rotational axes. All distances between adjacent addend positions are identical. The yellow bonds denote the positions of the malonate addends.
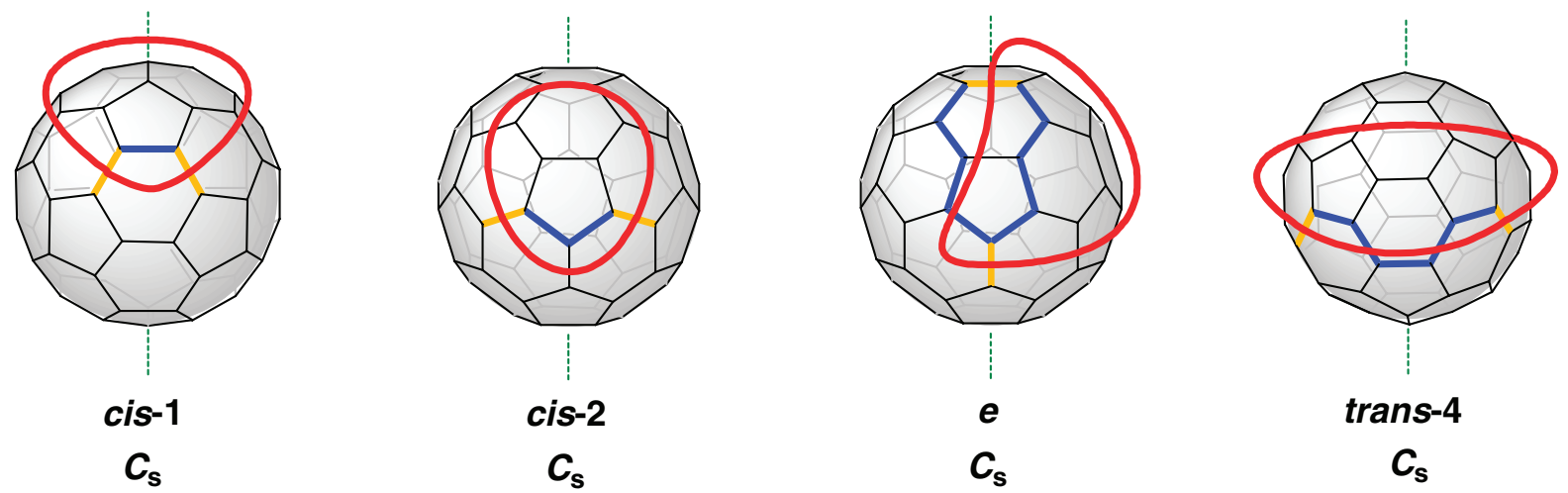

Fig. 5. Bisaddition patterns of $\mathrm{C}_{60}$ with $C_{5}$-symmetry. The two possible distances between adjacent positions are different. The yellow bonds denote the positions of the malonate addends.

ferent alkyl bridges are selected. Only this guarantees the most strain-free preorganization of the addends.

Trisadducts such as $\mathbf{2 0}$ and $\mathbf{2 2}$ exhibit $C_{3}$-symmetry and therefore are inherently chiral. Of course, it is highly desirable to achieve access to enantiomerically pure isomers. A few years ago we were able to isolate and characterize enantiom- erically pure trisadducts with an $e, e, e$-addition pattern and also a couple of further chiral bisadducts and trisadducts of $\mathrm{C}_{60} \cdot{ }^{10,36}$ This was accomplished by subsequent additions of chiral bisoxazolines which exhibit the same reactivity towards the cyclopropation of $\mathrm{C}_{60}$ as malonates. Since now the two stereoisomers of an adduct with an inherently chiral 


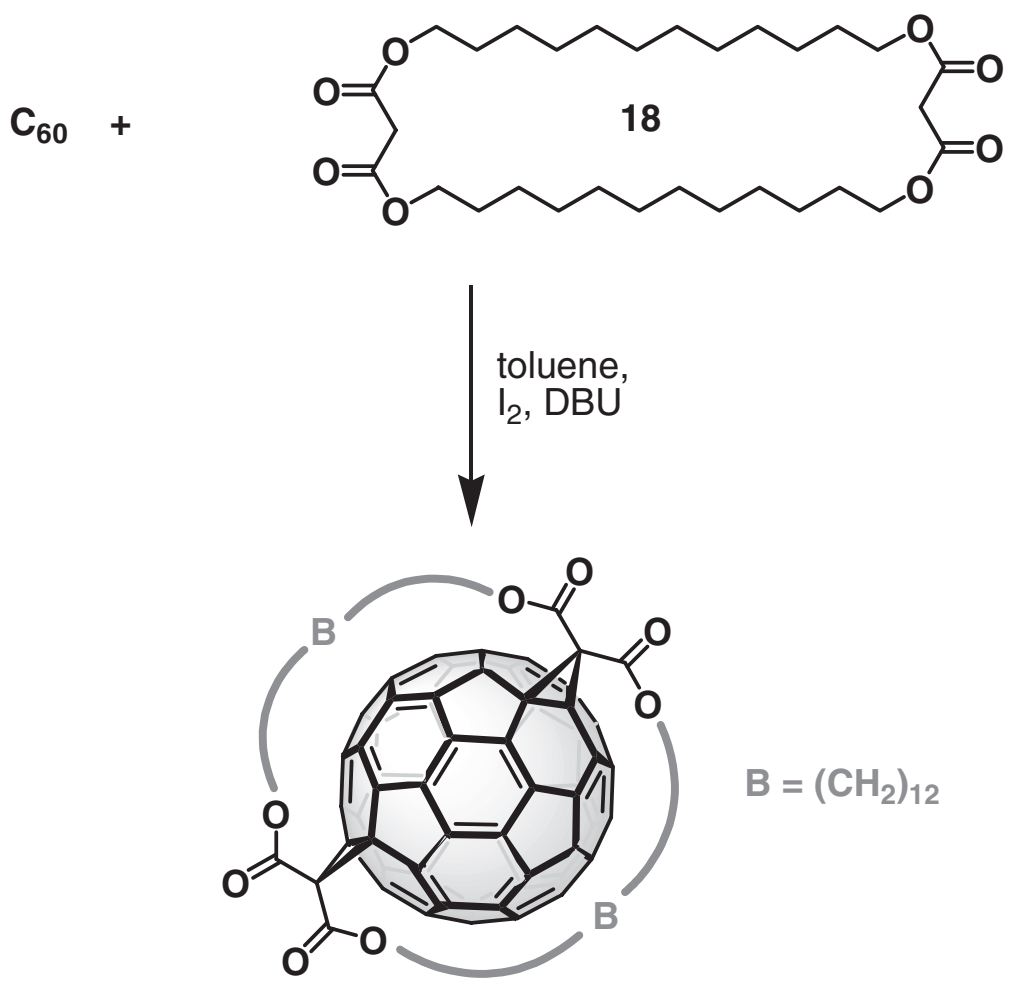

19

Scheme 4. Synthesis of the trans-3 bisadduct 19.

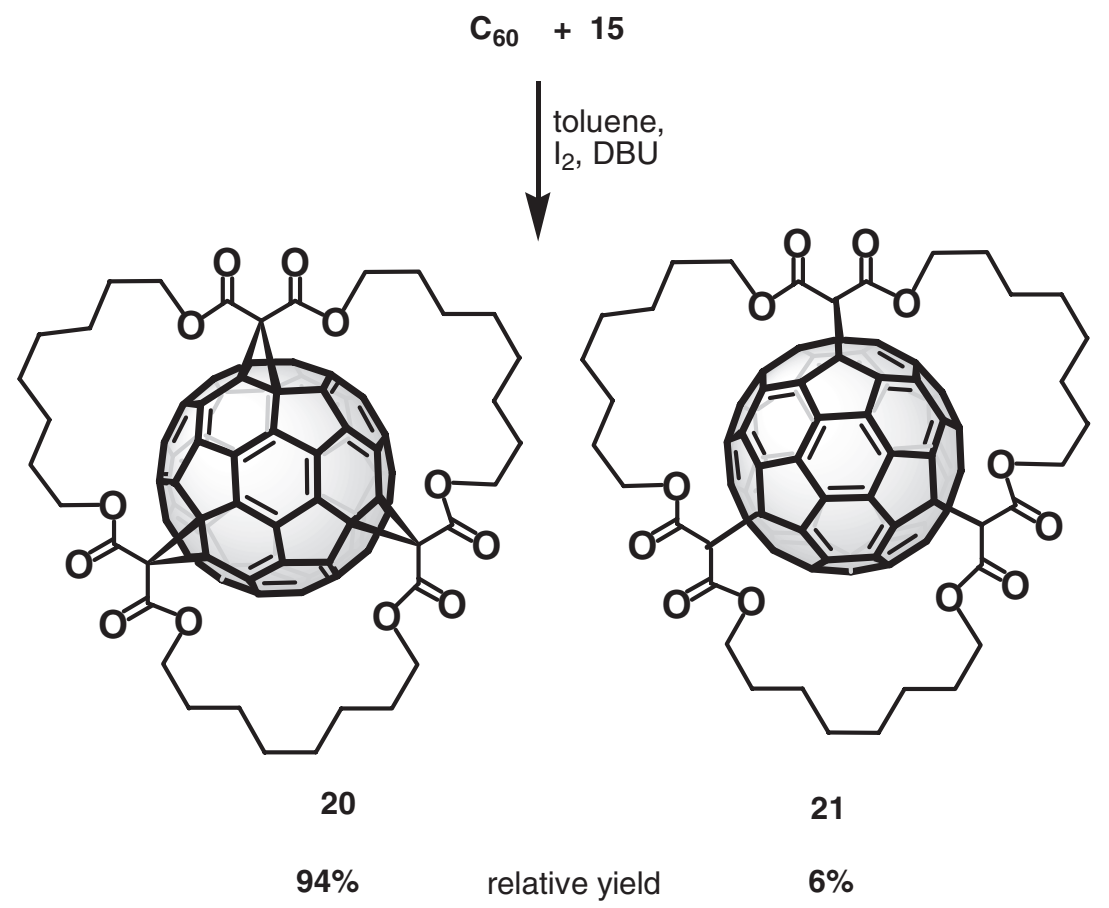

Scheme 5. Synthesis of the e,e,e-(20) and trans-4,trans-4,trans-4-(21) trisadducts. 


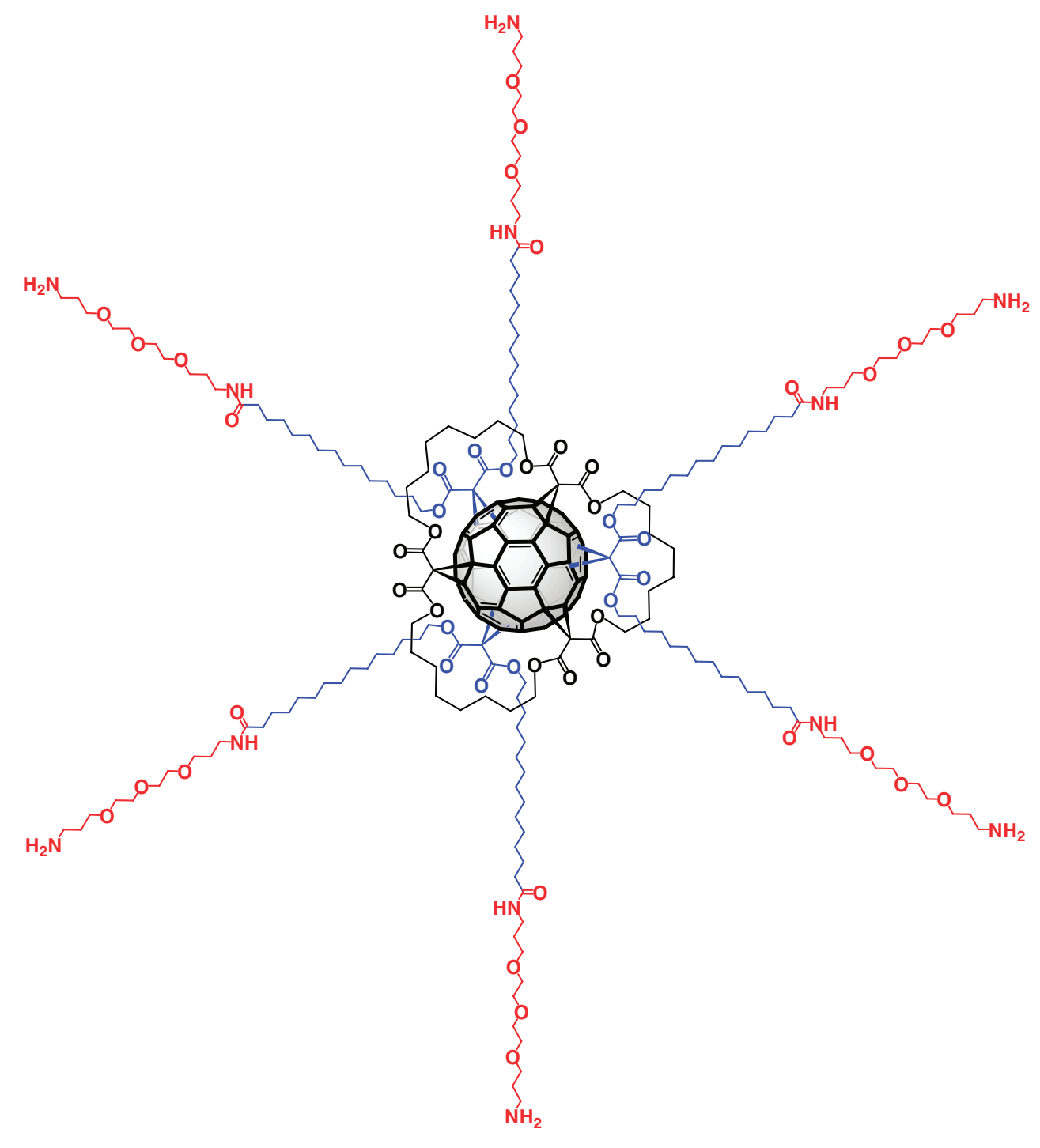

23

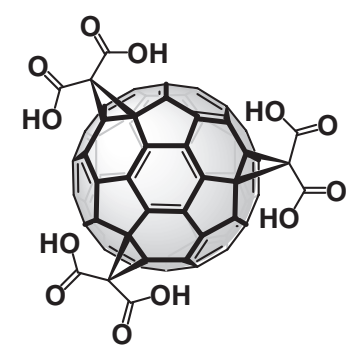

22

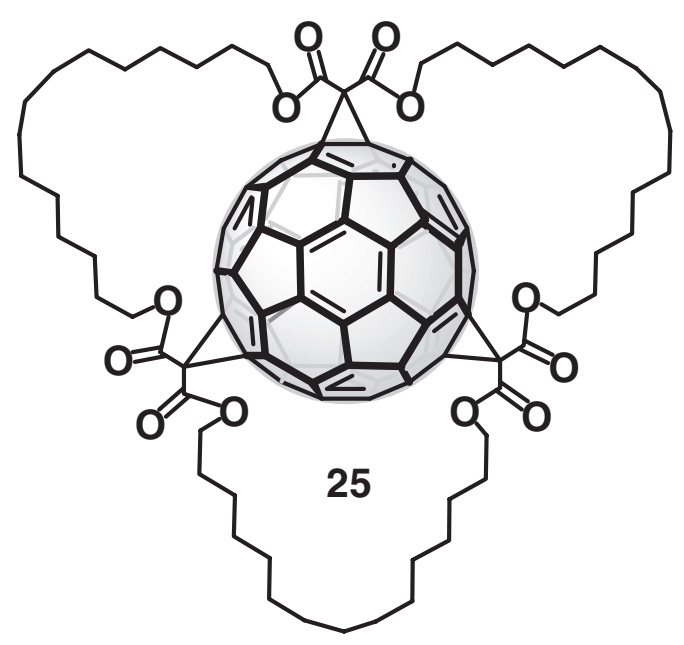




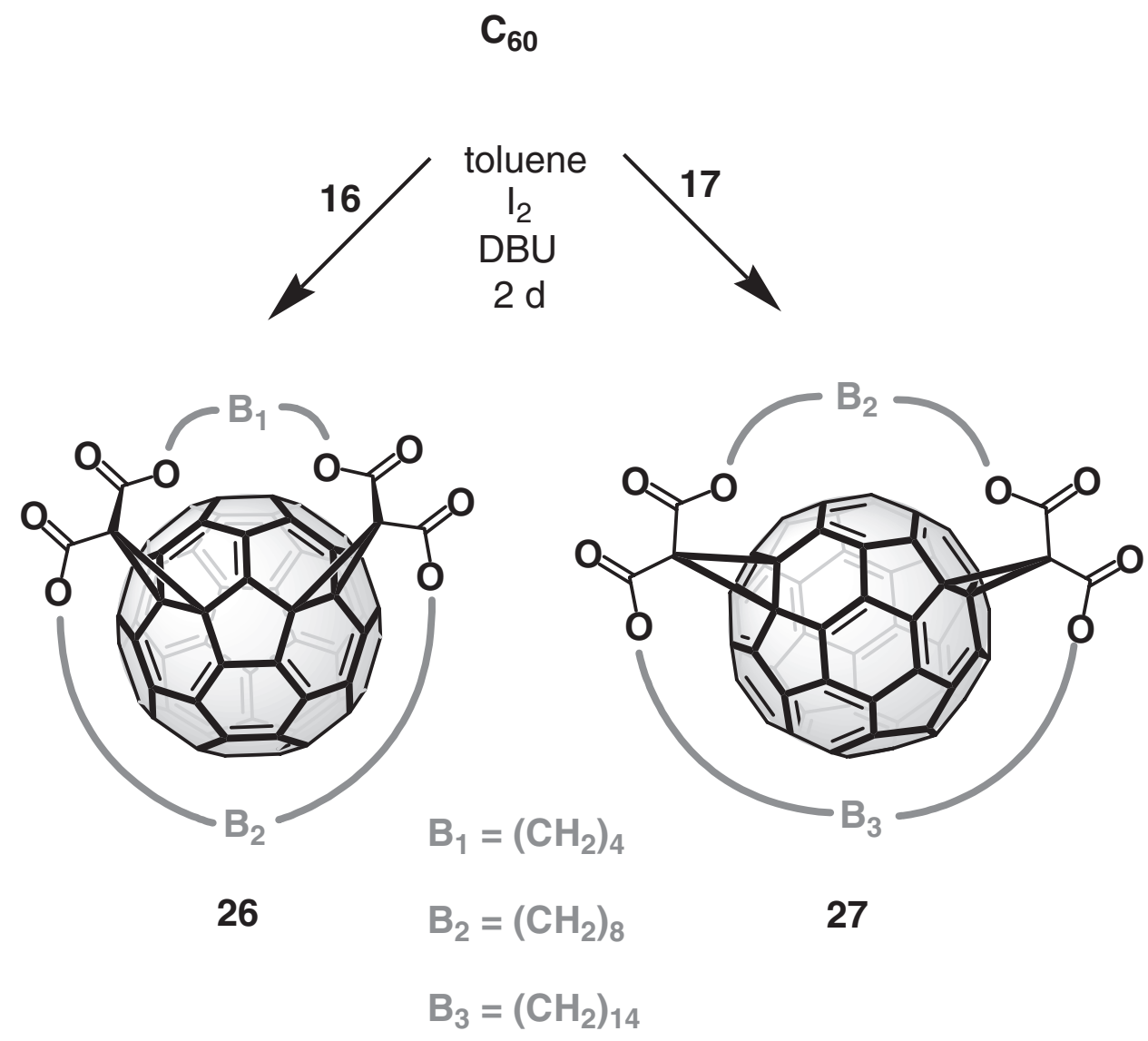

Scheme 6. Synthesis of of the cis-2 and $e$-bisadducts $\mathbf{2 6}$ and $\mathbf{2 7}$.

addition pattern represent a pair of diastereomers, isolation is possible by chromatography on an achiral stationary phases. We were able to investigate the chiroptical properties of a variety of enantiomerically pure bis- and trisadducts. Most importantly we succeeded in determining the absolute configuration by comparison of the calculated and experimental CD-spectra. ${ }^{10,36}$ More recently, we were able to achieve the regio- and stereoselective synthesis of trismalonates with a $C_{3}$-symmetrical $e, e, e$-addition pattern using chiral cyclo-[3]malonates. ${ }^{37}$ For this purpose we synthesized the enantiomerically pure trismalonate $\mathbf{2 8}$ in 4 steps starting from 3,4-O-isopropylidene-D-mannitol. Cyclopropanation of $\mathrm{C}_{60}$ with 28 afforded the $C_{3}$-symmetrical $e, e, e$-adducts 29 and $\mathbf{3 0}$ in $21 \%$ and $74 \%$ relative yield, respectively (Scheme 7). ${ }^{38}$ This corresponds to a de value of 53\%. The isolation of $\mathbf{2 9}$ and $\mathbf{3 0}$ was possible by chromatography on silica gel. Next to 29 and 30 the trans-4,trans-4,trans-4-adduct $\mathbf{3 1}$ exhibiting an achiral $C_{3 \mathrm{v}}$-symmetrical addition pattern was formed as a minor byproduct in $5 \%$ relative yield. The absolute configuration of 29 and $\mathbf{3 0}$ could be determined by the comparison of their CD-spectra with those of the related bisoxazoline adducts characterized previously. ${ }^{10}$

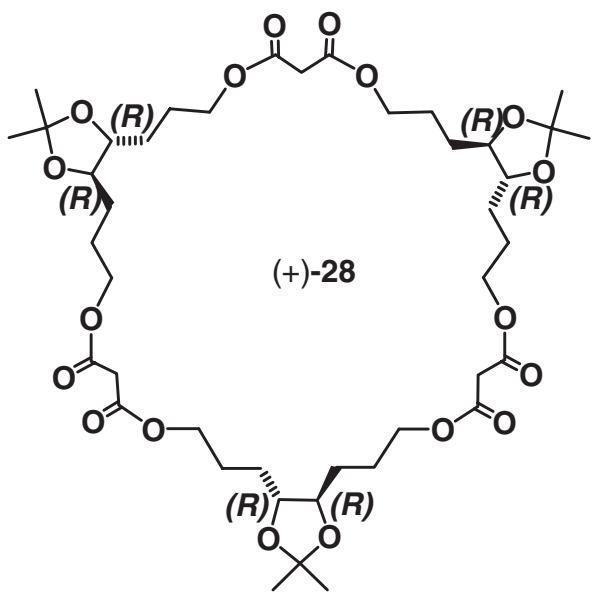

\section{Conclusions and Outlook}

We have presented efficient concepts for regio- and stereoselective bis- and trisadditions of malonates to $\mathrm{C}_{60}$. Either open-chain bipodal and tripodal malonates or cyclo- $[n]$-malonates can be used as precursor addends. Most of the malonate addends presented here are easily accessible from inexpensive starting mate- 


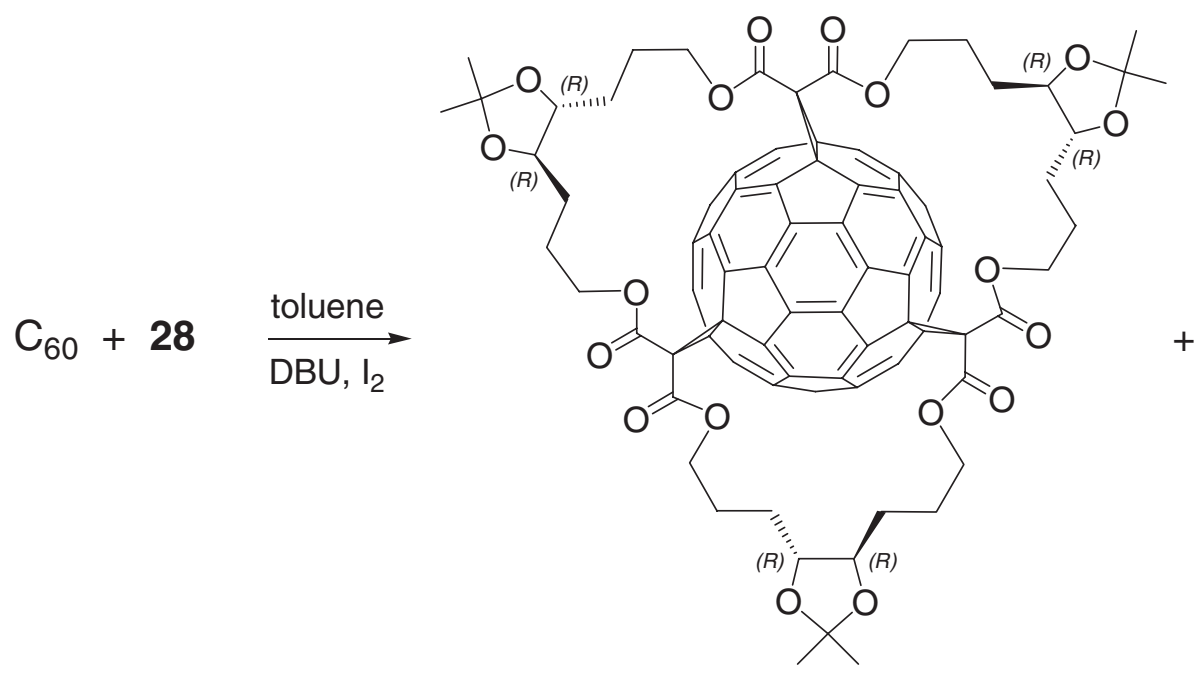

31

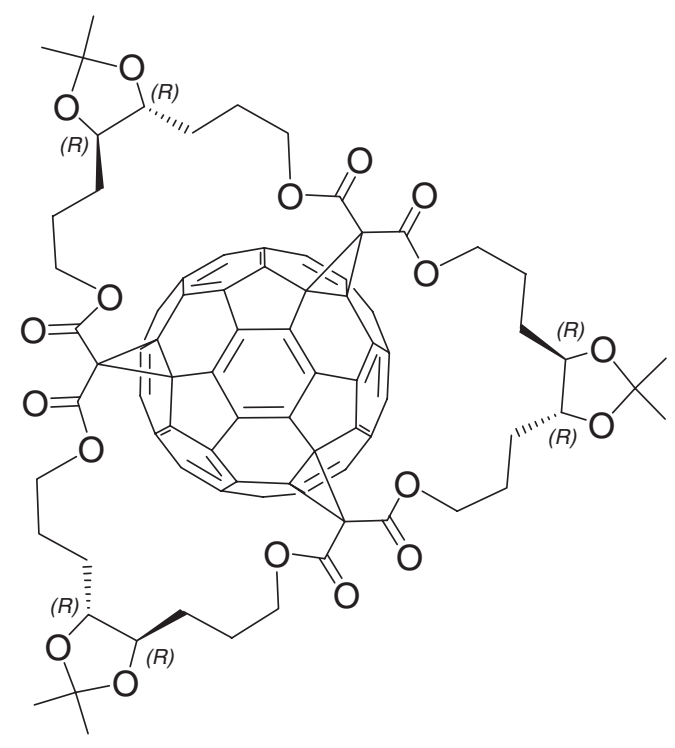

$(+)-29$

$\left(\right.$ all- $\left.R-{ }^{f} C-e, e, e\right)$
(all-R-trans-4,trans-4,trans-4)

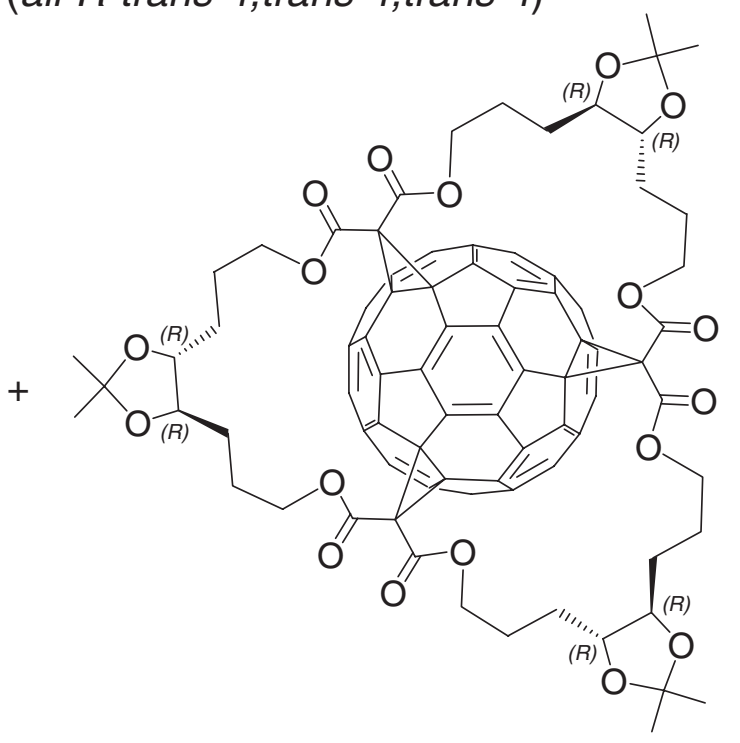

$(-)-30$

$\left(\right.$ all- $\left.R-{ }^{f} A-e, e, e\right)$

Scheme 7. Synthesis of the trans-4,trans-4,trans-4 (31) and the enantiomerically pure e,e,e-(29), (30) trisadducts.

rials. This is a very important prerequisite for possible applications of such stereochemcially defined multiple adducts. We have demonstrated that some of the bis- and trisadducts, such as the dyad $\mathbf{2}$ and the $e, e, e$-trismalonate $\mathbf{2 2}$ are interesting per se because of their remarkable photophysical or biological properties. However, and maybe even more importantly, they can serve as very useful building blocks for further chemical transformations. This is shown, for example, with the synthesis of the hexak- isadduct 23 involving an octahedral addition pattern. Compound $\mathbf{2 3}$ shows remarkable $\mathrm{pH}$-switchable aggregation properties in water. Fine tuning of the molecular and supramolecular properties of follow-up adducts such as $\mathbf{2 3}$ is possible because its stepwise formation process allows for the introduction of topologically distinct addend zones whose chemical nature can be varied over a wide range. The possibilities for structural and functional variations are very broad. 


\section{We gratefully acknowledge the Deutsche Forschungsgemeinschaft (Hi 468/14-1) for financial support.}

\section{REFERENCES}

[1] Hirsch, A.; Brettreich, M. Fullerene Chemistry and Reactions; Wiley-VCH: Weinheim; 2005.

[2] Mitshubishi's Frontier Carbon Inc.

[3] Bingel, C. Chem Ber 1993, 126, 1957.

[4] Lamparth, I.; Maichle-Moessmer, C.; Hirsch, A. Angew Chem Int Ed Engl 1995, 34, 1607.

[5] Hirsch, A.; Vostrowsky, O. Eur J Org Chem 2001, 5, 829.

[6] Hirsch, A.; Lamparth, I.; Karfunkel, H. R. Angew Chem 1994, 106, 453 (See also Angew Chem Int Ed Engl 1994, 34, 1437).

[7] Djojo, F.; Herzog, A.; Lamparth, I.; Hampel, F.; Hirsch, A. Chem Eur J 1996, 2, 1537.

[8] Hirsch, A. Top Curr Chem 1999, 199, 1.

[9] Hirsch, A.; Lamparth, I.; Groesser, T.; Karfunkel, H. R. J Am Chem Soc 1994, 116, 9385.

[10] Djojo, F.; Hirsch, A.; Grimme, S. Eur J Org Chem 1999, 11, 3027.

[11] Nierengarten, J.-F.; Gramlich, V.; Cardullo, F.; Diederich, F. Angew Chem Int Ed Engl 1996, 35, 2101.

[12] Nierengarten, J. F.; Habicher, T.; Kessinger, R.; Cardullo, F.; Diederich, F.; Gramlich, V.; Gisselbrecht, J. P.; Boudon, C.; Gross, M. Helv Chim Acta 1997, 80, 2238.

[13] Diederich, F.; Kessinger, R. Acc Chem Res 1999, 32, 537.

[14] Taki, M.; Sugita, S.; Nakamura, Y.; Kasashima, E.; Yashima, E.; Okamoto, Y.; Nishimura, J. J Am Chem Soc 1997, 119, 926.

[15] Ishi-i, T.; Shinkai, S. Chem Commun 1998, 9, 1047.

[16] Nakamura, E.; Isobe, H.; Tokuyama, H.; Sawamura, M. Chem Comun 1996, 15, 1747.

[17] Isobe, H.; Tokuyama, H.; Sawamura, M.; Nakamura, E. J Org Chem 1997, 62, 5034.

[18] van Eis, M. J.; Seiler, P.; Diederich, F.; Alvarado, R. J.; Echegoyen, L. Chem Commun 2000, 19, 1859.
[19] Woods, C. R.; Bourgeois, J.-P.; Seiler, P.; Diederich, F. Angew Chem, Int Ed 2000, 39, 3813.

[20] Qian, W.; Rubin, Y. Angew Chem, Int Ed 2000, 39, 3133.

[21] Sergeyev, S.; Diederich, F. Ang Chem Int Ed 2004, 43, 1738.

[22] Dietel, E.; Hirsch, A.; Eichhorn, E.; Rieker, A.; Hackbarth, S.; Roder, B. Chem Commun 1998, 1981.

[23] Guldi, D. M.; Luo, C.; Da Ros, T.; Prato, M.; Dietel, E.; Hirsch, A. Chem Commun 2000, 375.

[24] Guldi, D. M.; Luo, C.; Prato, M.; Dietel, E.; Hirsch, A. Chem Commun 2000, 373.

[25] Guldi, D. M.; Luo, C.; Prato, M.; Troisi, A.; Zerbetto, F.; Scheloske, M.; Dietel, E.; Bauer, W.; Hirsch, A. J Am Chem Soc 2001, 123, 9166.

[26] Guldi, D. M.; Hirsch, A.; Scheloske, M.; Dietel, E.; Troisi, A.; Zerbetto, F.; Prato, M. Chem Eur J 2003, 9, 4968.

[27] Sutton, L. R.; Scheloske, M.; Pirner, K. S.; Hirsch, A.; Guldi, D. M.; Gisselbrecht, J.-P. J Am Chem Soc 2004, 126, 10370.

[28] Dannhäuser, J.; Hampel, F.; Donaubauer, W.; Hirsch, A. unpublished results.

[29] Bourgeois, J.-P.; Diederich, F.; Echegoyen, L.; Nierengarten, J.-F. Helv Chim Acta 1998, 81, 1835.

[30] Soi, A.; Hirsch, A. New J Chem 1998, 22, 1337.

[31] Rapenne, G.; Diederich, F.; Crassous, J.; Collet, A.; Echegoyen, L. Chem Commun 1999, 1121.

[32] Beuerle, F.; Chronakis, N.; Hirsch, A. Chem Commun (in press) 2005.

[33] Reuther, U.; Brandmuller, T.; Donaubauer, W.; Hampel, F.; Hirsch, A. Chem Eur J 2002, 8, 2261.

[34] Dugan, L. L.; Turetsky, D. M.; Du, C.; Lobner, D.; Wheeler, M.; Almli, C. R.; Shen, C. K. F.; Luh, T.-Y.; Choi, D. W.; Lin, T.-S. Proc Natl Acad Sci USA 1997, 94, 9434.

[35] Braun, M.; Hartnagel, U.; Ravanelli, E.; Schade, B.; Boettcher, C.; Vostrowsky, O.; Hirsch, A. Eur J Org Chem 2004, 1983.

[36] Djojo, F.; Hirsch, A. Chem Eur J 1998, 4, 344.

[37] Chronakis, N.; Hirsch, A. Chem Commun 2005 (in press)

[38] For the introduction of the stereodescriptors ${ }^{\mathrm{f}} C$ and ${ }^{\mathrm{f}} A$ see: Thilgen, C.; Herrmann, A.; Diederich, F.; Helv Chim Acta 1997, 80, 183. 